\title{
The Increase Of Tooth Enamel Hardness Score After Cow Milk Immersion Compared To Artificial Saliva On Demineralized Tooth
}

\author{
Yendriwati,RizkaMalisaSinaga \\ Department ofOral Biology \\ Faculty of Dentistry, Universitas Sumatera Utara, Padang Bulan, Medan-20155, Indonesia. \\ Jl.Alumni No.2. Kampus USU. Medan 20155, Sumatera Utara, Indonesia
}

\begin{abstract}
Soft drinks and fruit juices with lower acidic $p H$ have become popular beverages in communities. Acidic beverages resulting demineralization on tooth cause a decrease of enamel hardness. In oral cavity, demineralized tooth is rescued by the buffering capacity of saliva as well as by drinking milk to accelerate tooth enamel remineralization. The aim of this study was to investigate the difference of enamel hardness score on tooth immersed in artificial saliva and cow milk. The present study was an experimental laboratory with pre and post test design. Thirty two maxillary first premolars were collected and randomly divided into 2 groups, with 16 samples each immersed in artificial saliva and cow milk. Samples were immersed in acidic solution for 5 min prior to exposing to cow milk (group 1) or artificial saliva (group 2) for 5 min twice a day until day3. Enamel hardness score was measured as follows : pre-treatment, post demineralization stage, and post treatment at dayl and day3 by Microvickers Hardness Tester. Data were analyzed using paired t-test and one way ANOVA. There was a significant difference $(p=0,000)$ on enamel hardness score of group 1 at dayl $(324,39 \pm 20.35 \mathrm{VHN})$ and day $3(354,80 \pm 21.09 \mathrm{VHN})$, as well as group 2 at dayl $(308,06 \pm 15,94 \mathrm{VHN})$ and day $3(322,18 \pm 16.94 \mathrm{VHN})$. Tooth enamel hardness on group 1 was significantly different to group 2 both at dayl $(p=0,018)$ and day 3 $(p=0,000)$. Those results suggest that artificial saliva and cow milk are able to increase the enamel hardness score. However, the efficacy of cow milk to augment the tooth enamel hardness is much higher than of artificial saliva is.
\end{abstract}

Keywords: Enamel hardness, remineralization, cow milk, artificial saliva

\section{Introduction}

Soft drinks mainly have acidic pH lower than 4 that may cause demineralization on tooth enamel. ${ }^{1}$ Demineralization is a process of enamel dissolution when the release of hydroxyapatites occur leading to micropores formation on enamel surface. ${ }^{2}$ Enamel consists of hydroxyapatite $\left(\mathrm{Ca}_{10}\left(\mathrm{PO}_{4}\right)_{6}(\mathrm{OH})_{2}\right)$ and fluorapatite $\left(\mathrm{Ca}_{10}\left(\mathrm{PO}_{4}\right)_{6} \mathrm{~F}_{2}\right)$. Hydroxyapatite has critical pH 5.5 whereas fluorapatite falls to $\mathrm{pH}$ 4.5. Owen et. al (2014) found that beverages with acidic $\mathrm{pH}$ such as sport and energy drinks, as well as orange juice initiated enamel dissolution by measuring percentage of tooth enamel weight loss. To decrease or prevent the risk of dental erosion can be achieved by (1) avoiding the direct contact of acidic foods or drinks on tooth surface thus discontinuing the process of tooth demineralization, (2) applying remineralizing agents immediately after consuming foods or drinks by fluoride mouth rinse, and (3) drinking milk to accelerate remineralization process. ${ }^{4}$

Normally, the saliva buffering capacity neutralizes the low $\mathrm{pH}$ in oral cavity when acidic condition is present and increases saliva $\mathrm{pH}$ followed by remineralization.Remineralization is a process of restoring phosphate and calcium ions on tooth enamel surface when oral cavity $\mathrm{pH}$ returns to neutral. ${ }^{5}$ During remineralization, it requires minerals such as calcium, phosphate, magnesium and fluoride to promote tooth calcification. Calcium and phosphate are commonly found in cow milk and its product (e.g. yogurt and cheese), soy milk, salmon fish and broccoli, whereas water, seafood, yogurt and cheese are source of fluor. ${ }^{6}$

Cow milk has the ability to protect tooth from erosion, particularly if consumed immediately following acids intake. It has been shown to enhance tooth enamel remineralizationdue to casein, calcium and phosphate in content. ${ }^{1,7}$ Amoraset. al (2012) found that cow milk was able to maintain demineralization process from hydrochlorite acid toward advanced stage, which observed in an increased enamel surface hardness. ${ }^{7}$ Lachowski et. al (2014) investigated that cow milk could increase tooth enamel surface hardness, so that decrease the potential of dental erosion. The reduction of enamel surface hardness on orange juice-immersed tooth was higher than on orange juice-immersed tooth followed by milk immersion. ${ }^{1}$

Demineralization and remineralization process are associated with tooth enamel surface hardness. Hardness is defined as a resistance of solid matter to penetration. ${ }^{8}$ Tooth hardness is influenced by the level of 
phosphate and calcium of enamel, called hydroxyapatite, in which the amount of hydroxyapatite relates to the thickness of enamel. ${ }^{9}$

The aim of this study was to investigate the difference of tooth enamel hardness score after artificial saliva or cow milk immersion of demineralized tooth.

\section{Materials And Methods}

This study was an experimental laboratory with pre and post test design conducted in LaboratoriumTeknikMesin UNIMED and LaboratoriumBiologi FMIPA UNIMED. Inclusion criteria as follows: the extracted maxillary first premolar collected from patients age 17-30 years with normal size, shape, and tooth structure, and the crown must be intact.Exclusion criteria are caries tooth or erosion, attrition, and abrasion tooth, dental filling, tooth with endodontic treatment, cracked tooth, fracture, necrosis and whitened tooth. Samples were thirty two maxillary first premolar extracted from patients that fulfill the inclusion and exclusion criteria.

Tooth was thoroughly cut at cemento-enemeljunction that subsequently separate the root and crown part completely. Palatal surface of the crown was coated with nail varnish, thenwas implanted in acrylic. Each tooth was randomly numbered and divided into two groups. Tooth enamel hardness was measured prior to sample treatment.All samples were immersed in acid solution for $5 \mathrm{~min}$ to demineralize tooth. Group 1 was stored in cow milk for 5 min twice a day at 11.00 and 17.00. Group 2 was stored in artificial saliva for $5 \mathrm{~min}$ twice a day at 11.30 and 17.30. Samples were immersed in aquabidest and incubated at $37^{\circ} \mathrm{C}$. Experiment was performed for 3 days.Enamel hardness score of samples on pre and post acid immersion was assessed on day 1. Hardness score of tooth immersed in cow milk and artificial saliva on day 1 was measured on day 2, whereas tooth immersed on day 3 was measured on day 4 using Microvickers Hardness Testerwith load $100 \mathrm{~g}$ for 15 sec.This study was approved by The Medical Research Ethics Committee, Faculty of Medicine, University of Sumatera Utara, No. 312/KOMET/FK USU/2016 on April 14, 2016.Data were analyzed using paired t-test and one way ANOVA with post hoc test.

\section{Result}

Table 1 shows the average of enamel hardness scores on pre and post treatment including acidic solution, cow milk and saliva immersion. Enamel hardness score is decreased in all samples post acid immersion compared to pre treatment samples. However, the increased enamel hardness score is shown at day1 and day3 post treatment in both groups compare with post acid treatment.

Table 1.The average of enamel hardness score on pre and post treatment (acid, cow milk and saliva) at day1 and day3.

\begin{tabular}{|c|c|c|}
\hline Type of treatment & $\begin{array}{c}\text { Group I } \\
\text { (Cow milk) X } \pm S D \\
\text { (VHN) }\end{array}$ & $\begin{array}{c}\text { Group II (Artificial saliva) } \\
\text { X } \pm \text { SD (VHN) }\end{array}$ \\
\hline Pre treatment & $376,23 \pm 16,94$ & $373,22 \pm 15,08$ \\
\hline Post demineralization & $309,62 \pm 18,44$ & $301,18 \pm 15,44$ \\
\hline $\begin{array}{c}\text { Remineralization agent } \\
\text { treatment day1 }\end{array}$ & $324,39 \pm 20.35$ & $308,06 \pm 15,94$ \\
\hline $\begin{array}{c}\text { Remineralization agent } \\
\text { treatment day3 }\end{array}$ & $354,80 \pm 21.09$ & $322,18 \pm 16.94$ \\
\hline
\end{tabular}

Paired t-test analysis shows that enamel hardness score in cow milk-immersed samples at day 3 is significantly higher than samples at day $1(\mathrm{p}<0.05)$ (Table 2$)$.

Table 2. The difference of enamel hardness score after cow milk immersion at day 1 and day 3 analyzed by paired t-test.

\begin{tabular}{|l|c|c|c|}
\hline Time of immersion & $\mathrm{X} \pm \overline{\mathrm{SD}}(\mathrm{VHN})$ & $\Delta \overline{\mathrm{X}}(\mathrm{VHN})$ & Sig. $(\mathrm{p})$ \\
\hline Day 1 & $324,39 \pm 20.35$ & & \multirow{2}{|c|}{$30,000^{*}$} \\
\hline Day 3 & $354,80 \pm 21.09$ & 30,41 & 0,00 \\
\hline
\end{tabular}

*level of significance, $\mathrm{p}<0.05$

Enamel hardness score in artificial saliva treated group at day 3 is significantly increased compared to day 1 analyzed by paired t-test $(\mathrm{p}<0.05)$ (Table 3$)$.

Tabel 3.The difference of enamel hardness score after artificial saliva immersion at day 1 and day 3 analyzed by paired t-test.

\begin{tabular}{|l|c|c|c|}
\hline $\begin{array}{c}\text { Time of } \\
\text { immersion }\end{array}$ & $\overline{\mathrm{X}} \pm \mathrm{SD}(\mathrm{VHN})$ & $\overline{\Delta \mathrm{X}}(\mathrm{VHN})$ & Sig. (p) \\
\hline Day 1 & $308,06 \pm 15,94$ & \multirow{2}{|c|}{14,12} & $0,000^{*}$ \\
\hline Day 3 & $322,18 \pm 16.94$ & 12 & 0 \\
\hline
\end{tabular}


*level of significance, $\mathrm{p}<0.05$

One way ANOVA was used to determine the difference of enamel hardness score after cow milk and artificial saliva immersion in each time course with level of significance $p=0.000(p<0.05)$. There is a significantly different hardness score of tooth enamel soaked in cow milk and artificial saliva at each time point. Additionally, to determine which of group is significantly different from the others, LSD post hoc test was used (Table 4).

Table 4. LSD test showing the enamel hardness score after cow milk and artificial saliva immersion at day 1 and day 3

\begin{tabular}{|l|c|c|c|c|}
\hline \multirow{3}{*}{ Cow milk } & \multicolumn{4}{|c|}{ Artificial saliva } \\
\cline { 2 - 5 } & \multicolumn{3}{|c|}{ Day 1 } & \multicolumn{2}{c|}{ Day 3 } \\
\cline { 2 - 5 } & $\overline{\Delta \mathrm{X}}(\mathrm{VHN})$ & Sig. (p) & $\overline{\Delta \mathrm{X}}(\mathrm{VHN})$ & Sig. (p) \\
\hline Day 1 & 16,33 & $0.018^{*}$ & 2,21 & 0.740 \\
\hline Day 3 & 46,74 & $0.000^{*}$ & 32,62 & $0.000^{*}$ \\
\hline
\end{tabular}

*level of significance, $\mathrm{p}<0.05$

\section{DISCUSSION}

Enamel hardness varies in type and location of the measured tooth. Chemical composition and enamel thickness may take part in each tooth. The present study was done to quantitate enamel hardness on buccal surface and the representative data were subsequently selected for each measurement. Initial hardness measurement (table 1) shows the distinct values of standard deviation in every group. Palti DG, et al. (2008) found the enamel hardness score in pre-treatment group ranges from 367,13-399,97 VHN. ${ }^{10}$ Meanwhile, the present study showed the average value ranging from 358,48-390,58 VHN.Palti DG selected premolar 4-10 years after eruption as a model sample, whereas this study used premolar from patient in age of 17-30 years implying that the tooth has been erupted 6-19 years.

The tooth period in oral cavity is one of the factors affecting the enamel hardness. Enamel surfaceson maturation stage post eruption eventually contact to saliva and the dynamic process between demineralization and remineralization occurs during and after tooth eruption.Samples were immersed in acid solution for 5 min and the hardness score was measured. The decreased enamel hardness score after acid immersion was observed, indicating that acidic solution might reduce enamel hardness. The $\mathrm{pH}$ value of solution used in this study (3.6) is much lower than the critical $\mathrm{pH}$ of hydroxyapatite (5.5). Direct contact between hydroxyapatite and solution with low $\mathrm{pH}(<5.5)$ leads to enamel mineral dissolution that may influence enamel hardness. ${ }^{4}$ There are some factors affecting the rate of enamel dissolution, such as acidity level $(\mathrm{pH})$, concentration, mineral ion composition and saliva flow, saliva buffering capacity, diet (quantity and frequency of carbohydrate intake), and tooth structure. , $11^{-11}$

Furthermore, samples were immersed in cow milk (group 1) and artificial saliva (group 2). Enamel hardness score was increased both at day1 and day3, due to the presence of remineralization process on tooth. Remineralization is a process to restore mineral ions into hydroxyapatite structure. ${ }^{5}$ Adequate saliva flow rate, presence of calcium, phosphate, as well as fluoride, and neutral $\mathrm{pH}$ of oral cavity are the factors involved in remineralization. ${ }^{11}$ Preserved foods and high glucose diet may predispose to inadequate remineralization. Therefore, remineralization activity needs to boost in order to maintain enamel strength, e.g. providing mineralization agents that release calcium and phosphate ions to enamel surface, calculus-forming free, resistance to lower $\mathrm{pH}$ (acid), stimulating remineralization in saliva and appropriate for patient with xerostomia. $^{12}$

Table 2 shows there is a significant difference $(\mathrm{p}<0.05)$ of enamel hardness score in group 1 (cow milk) at day 1 and day 3 analyzed by Paired t-test. According to these results, it indicates that cow milk could increase enamel hardness at day1 and get much higher at day3. Calciums and phosphors in cow milk play an important role during remineralization so that increase enamel hardness. In contrast, Amoraset. al (2012) found that the enamel hardness was increased but not significant in cow milk-immersed tooth which was presoaked in $\mathrm{HCl}$ prior to milk immersion. ${ }^{7}$ The tooth immersion was performed for 4 times 1 min each, which was rather shorter in time. In addition, different mineral level in cow milk content used may affect the result.

Enamel hardness score in cow milk-immersed tooth at day3 is higher than that at day 1 with the difference as $30.41 \mathrm{VHN}$. The longer and more frequent the enamel is exposed to calcium and phosphor containing beverages, the more minerals the enamel takes up so that may raise the hardness of enamel.Milk is a cellular emulsion mainly containing casein that is composed of a thousand protein molecules bound to calcium and phosphate. ${ }^{13}$ Drinking milk immediately after tooth exposed to acid is a good alternative due to its ability to protect tooth from erosion. Milk acts as remineralization agent, as well as increases mineral deposit and organic material on enamel surface, and forms a protective film. This film is associated to casein adsorption on the surface of enamel to reduce the dissolved hydroxyapatite crystals and to prevent ions discharge. ${ }^{1}$ High calcium 
beverages show the reduced erosion formation and increase remineralization. Not only to modify the potency of erosion, the addition of calcium may also alter the basic nature of beverages such as taste and color. Therefore, drinking milk or any others with naturally calcium source is much more preferable to consume. ${ }^{7}$

Carbohydrate in cow milk is composed of $80 \%$ lactose. Lactose is fermented by bacteria in oral cavity to be lactic acid, which can lower $\mathrm{pH}$ into 6.0. This carbohydrate has potentially low cariogenicity in a normal condition. ${ }^{14}$ However, for particular circumstances milk may cause caries in children if consumed by using bottle during sleeping time. The decreased saliva flow rate is associated to the bottle caries in children that reduce the saliva neutralization capacity. When the kid is falling asleep, the oral cavity is overwhelmed with milk that eventually immerse the teeth leading to prolonged fermentation time of carbohydrate. The fermented carbohydrate produces acid to initiate enamel demineralization so that caries may occur. ${ }^{15}$

Drinking milk from a bottle at night is acceptable as long as the kids must brush their teeth before sleep. Milk for daily needs may reduce $\mathrm{pH}$ on plaque 10 min after drinking $(6,79)$ due to fermentation of lactose in the milk. Yet, this $\mathrm{pH}$ begins to rise 20 min afterward as peptides and amino acids produced by the hydrolysis of casein may increase $\mathrm{pH}$ on plaque and prevent the tooth to demineralize. ${ }^{14}$ Fermentation of lactose in oral cavity can be dismissed by gargling with water for 5 min after drinking milk.

Paired t-test in artificial saliva groups (Table 3 ) shows that there is a significant difference $(\mathrm{p}<0.05)$ of enamel hardness score at day 1 and day3. Hardness score at day3 is much higher than that at day1 as much as 14.12 VHN.

There are various minerals such as potassium hydrogen phosphate, calcium phosphate, potassium thiocyanate, sodium chloride, potassium chloride and urea.

Several mechanisms involved in functionally protective saliva from erosion, that is firstly, the direct action of saliva against the agent of erosion by liquefying, cleansing, neutralizing, and buffering of saliva. Secondly, organic components of saliva form thin pellicle on enamel surface that may act to defend from direct contact between acid and tooth surface, thus affecting the dissolution level of tooth hard tissue. Thirdly, the existence of calcium and phosphate ions in saliva can become natural resources to a new crystal formation. ${ }^{16}$ Those functions mentioned above indicate that saliva has a potential ability to increase enamel hardness score as a result of remineralization.

This study shows that there is a difference of enamel hardness on tooth-immersed cow milk and artificial saliva in each time of immersion. According to one way ANOVA test, there is a difference of hardness score in each time point of all groups. LSD test (table 4) shows the significant difference of tooth enamel hardness in cow milk-treated group compare with artificial saliva-treated group at day1 and in cow milk-treated group compare with artificial saliva-treated group at day3 $(\mathrm{p}<0.05)$.The average of hardness score difference between cow milk and artificial saliva-treated group at day1 is $16.33 \mathrm{VHN}$, whereas at day3 is $32.62 \mathrm{VHN}$.

According to those results, cow milk increases the enamel hardness much higher than artificial saliva does. Distinct calcium and phosphor contents in those two sources may affect remineralization so the enamel hardness score is also different in those groups. Moreover, milk, but not artificial saliva, contains casein that is rapidly adsorbed onto enamel surface to raise enamel resistanceagainst acid.Cow milk has approximately $\mathrm{pH} 6.5$ and artificial saliva has $\mathrm{pH} 6.8$ suggesting that the $\mathrm{pH}$ of milk is much lower than $\mathrm{pH}$ of artificial saliva is. Yet, the lower $\mathrm{pH}$ of milk does not have any notable impact on remineralization.

\section{Conclusions}

It is concluded that both cow milk and artificial saliva may enhance the enamel hardness. However, cow milk has the better capability to raise the enamel hardness than artificial saliva does.

\section{References}

[1]. Lachowski KM, Ferreira D, de Oliveira TA, Sobral MAP. Effect of the mixture of coffee or chocolate to milk in the progression of des-remineralization of tooth enamel - an in vitro study. Braz Research in Pediatric Dent and Integrated Clinic 2014; 14: 183-9.

[2]. Miller KR. Remineralization strategies. http://www.rdhmag.com/articles/print/volume-26/issue7/feature/remineralizationstrategies.html (8 Oktober 2015).

[3]. Yamamoto ETC, Vanderlei A, Amaral R, Nicolo RD, da Rocha JC, de Araujo MAM. Influence of three types of drinks on the surface of human dental enamel: in vitro study. Rev GauchaOdontol 2013; 61(1): 42.

[4]. Owens BM, Malette JD, Phebus JG. Effect of carbonated cola beverages, sports and energy drinks and orange juice on primary and permanent enamel dissolution. Austin J Dent 2014; 1: 1-2.

[5]. Widyaningtyas V, Rahayu YC, Barid I. Analisispeningkatanremineralisasi enamel gigisetelahdirendamdalamsusukedelaimurni (Glycine max (L.) merill) menggunakanscanning electron microscope (SEM). J PustakaKesehatan 2014; 2: 258-61.

[6]. Stegeman CA, Davis JR. The dental hygienist's guide to nutritional care. 3 th ed., Missouri: Saunders Elsevier, 2010: 146.

[7]. Amoras DR, Corona ASM, Rodrigues Jr AL, Serra MC. Effect of beverages on bovine dental enamel subjected to erosive challenge with hydrochloric acid. Braz Dent J 2012; 23: 367-71.

[8]. McCabe JF, Walls AWG. Bahankedokterangigi. AlihBahasa. Sunarinstyas S, Mustaqimah DN. Jakarta: EGC, 2015: 19-20.

[9]. Gutierrez-Salazar MDP, Reyes-Gasga J. Microhardness and chemical composition of human tooth. Material Research 2003; 6: 367 8.

[10]. Palti DG, Machado MAAM, Silva SMB, Abdo RCC, Lima JEO. Evaluation of superficial microhardness in dental enamel with different eruptive ages. Braz Oral Res, 2008; 22 (4): 313-4.

[11]. Collin FM. Treatment options for tooth discoloration and remineralization. Pennwell, 2008: 5 
TheIncrease Of Tooth Enamel Hardness Score After Cow Milk.....

[12]. Hemagaran G, Neelakantan P. Remineralization of the tooth structure - the future of dentistry. Int J of PharmTech Research 2014; 6(2): 487-91.

[13]. Davari AR, Kazemi ARD, Ataei E, Vatanpour M, Abdollahi H. Effects of bleaching and remineralising agents on the surface hardness of enamel. J Dent Shiraz Univ Med Scien 2012; 13(4): 157-8.

[14]. Telgi RL, Yadav V, Telgi CR, Boppana N. In vivo dental plaque pH after consumption of dairy products. General Dentistry 2013. 56-7.

[15]. Zafar S, Harnekar SY, SiddiqiA.Early childhood caries: etiology, clinical considerations, consequences and 